\title{
Farklı organik gübre ve dozlarının toprak özellikleri üzerine etkilerinin belirlenmesi
}

\section{Determination of the effects of different organic fertilizers and doses on soil properties}

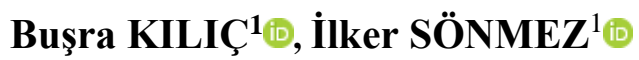 \\ ${ }^{1}$ Akdeniz Üniversitesi Ziraat Fakültesi Toprak Bilimi ve Bitki Besleme Bölümü,07058, Antalya \\ Sorumlu yazar (Corresponding author): İ. Sönmez, e-posta (e-mail): ilkersonmez@akdeniz.edu.tr \\ Yazar(lar) e-posta (Author e-mail): busra.bjk.92@ hotmail.com
}

\section{MAKALE BİLGISİ}

Alınış tarihi 12 Mart 2019

Düzeltilme tarihi 19 Nisan 2019

Kabul tarihi 26 Nisan 2019

\section{Anahtar Kelimeler:}

Organik gübre

Leonardit

Vermikompost

Çiftlik gübresi

Tavuk gübresi

\begin{abstract}
ÖZ
Organik gübreleme topraklarda verimlilik parametrelerinin artırılmasında kullanılan en etkili yöntemlerden birisidir. Organik gübreler toprak özelliklerinde iyileștirmeler sağlarken bir yandan da üzerinde yetiştirilen bitkilere verim ve kalite açısından katkı sağlamaktadırlar. Bu çalışmada; organik gübre olarak Tavuk Gübresi (TG) $\left(0 \mathrm{~kg} \mathrm{da}, 100 \mathrm{~kg} \mathrm{da}^{-1}, 200 \mathrm{~kg} \mathrm{da}^{-1}, 300\right.$ $\left.\mathrm{kg} \mathrm{da}^{-1}\right)$, Çiftlik Gübresi (ÇG) $\left(0 \mathrm{~kg} \mathrm{da}^{-1}, 100 \mathrm{~kg} \mathrm{da}^{-1}, 200 \mathrm{~kg} \mathrm{da}^{-1}, 300 \mathrm{~kg} \mathrm{da}^{-1}\right)$, Vermikompost (V) $\left(0 \mathrm{~kg} \mathrm{da}^{-1}, 100 \mathrm{~kg} \mathrm{da}^{-1}, 200 \mathrm{~kg} \mathrm{da}^{-1}, 300 \mathrm{~kg} \mathrm{da}^{-1}\right)$ ve Leonarditin (L) $\left(0 \mathrm{~kg} \mathrm{da}^{-1}, 50 \mathrm{~kg} \mathrm{da}^{-1}\right.$, $100 \mathrm{~kg} \mathrm{da}^{-1}, 200 \mathrm{~kg} \mathrm{da}^{-1}$ ) artan dozlarının dört tekerrürlü olarak saksı koșullarında marul yetiştirilen toprakların bazı fiziksel ve kimyasal özellikleri üzerine olan etkileri belirlenmeye çalışılmıştır. Farklı organik gübrelerin topraklarda pH, EC, organik madde, N, P, K, Ca, Zn ve $\mathrm{Cu}$ içeriklerinde özellikle TG ve ÇG uygulamaları etkili olmuştur. Uygulama dozları bakımından yapılan değerlendirmede ise $\mathrm{EC}$, organik madde, N, P, K, Ca, Fe ve Mn içeriklerinde doz etkileri önemli olarak belirlenmiș ve genel olarak $200 \mathrm{~kg} \mathrm{da}^{-1}$ ve $300 \mathrm{~kg} \mathrm{da}^{-1}$ dozları öne çıkmıştır. Farklı organik gübrelerin toprak özellikleri üzerine etkilerinin belirlenmesi açısından birlikte uygulamaların yapılmasının en iyi materyal, doz ve kombinasyonların belirlenmesinde avantaj sağlayabileceği görülmektedir.
\end{abstract}

\section{ARTICLE INFO}

Received 12 March 2019

Received in revised form 19 April 2019

Accepted 26 April 2019

Keywords:

Organic manure

Leonardite

Vermicompost

Farmyard manure

Poultry manure

\begin{abstract}
Organic fertilization is one of the most effective methods used to increase fertility parameters in the soil. While organic fertilizers provide improvements in soil characteristics, they also contribute to plants grown on it in terms of productivity and quality. In this study; the effects of increasing the doses of chicken manure (PM) $\left(0 \mathrm{~kg} \mathrm{da}, 100 \mathrm{~kg} \mathrm{da}^{-1}, 200 \mathrm{~kg} \mathrm{da}^{-1}, 300\right.$

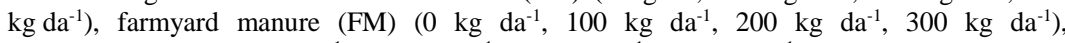
vermicompost (V) $\left(0 \mathrm{~kg} \mathrm{da}^{-1}, 100 \mathrm{~kg} \mathrm{da}^{-1}, 200 \mathrm{~kg} \mathrm{da}^{-1}, 300 \mathrm{~kg} \mathrm{da}^{-1}\right)$ and Leonardite (L) (0 $\mathrm{kg} \mathrm{da}^{-1}, 50 \mathrm{~kg} \mathrm{da}{ }^{-1}, 100 \mathrm{~kg} \mathrm{da}{ }^{-1}, 200 \mathrm{~kg} \mathrm{da}^{-1}$ ) as organic fertilizers on some physical and chemical properties of soils grown in pot conditions under four replications were determined. Especially (TG) and (ÇG) applications are effective in terms of $\mathrm{pH}, \mathrm{EC}$, organic materials, $\mathrm{N}$, $\mathrm{P}, \mathrm{K}, \mathrm{CA}, \mathrm{Zn}$ and $\mathrm{Cu}$ contents of soils. Dose effects were determined to be important for EC, organic materials, $\mathrm{N}, \mathrm{P}, \mathrm{K}, \mathrm{Ca}, \mathrm{Fe}, \mathrm{Mn}$ and second $\left(200 \mathrm{~kg} \mathrm{da}^{-1}\right)$ and third $\left(300 \mathrm{~kg} \mathrm{da}^{-1}\right)$ doses became prominent and were more effective. To determine the effects of different manures on soils, combined applications to state the best material, dose and combinations can provide an advantage.
\end{abstract}

\section{Giriş}

Organik gübreler; bitkisel ve hayvansal atık ve artıklarından oluşan, uygulandıkları toprakların yapısal özelliklerini iyileştiren, bitkilere besin takviyesinde bulunan ve topraklardaki besin elementlerinin alımlarını kolaylaştıran gübreler olarak bilinmektedir. Ayrıca organik maddenin toprağın iziksel, kimyasal ve biyolojik özelliklerini olumlu etkilediği uzun süredir bilinmektedir (Shirani ve ark. 2002). Entansif tarım tekniklerinde toprakların her yıl kullanılmaları ve iklimsel faktörler sonucu azalan organik madde düzeyleri toprakta bulunan bitki besin elementlerinin alınımını güçleştirmektedir. 
Türkiye topraklarında ekim yapılan arazilerinin büyük çoğunluğu killi tekstürlü olduğu için toprak sert bir yapıya sahip olmaktadır ve bu da bitkinin gelişimini güçleştirmektedir.

Türkiye koşullarında düşük organik madde düzeyleri tarımda önemli oranda verimliliği etkilemektedir (Eyüpoğlu 1998; Gezgin ve ark. 1999). Bu amaçla organik gübreler de inorganik besin maddeleri kadar kalite üzerinde etkili olmaktadır. Ülke topraklarımızın organik madde içeriklerinin düşük olması ve besin elementleri eksikliği, organik gübrelerin topraklara verilmesinin gerekliliği ve önemini ortaya çıkarmaktadır. Organik gübrelerin bütün besin maddelerini az veya çok içermesinden dolayı bitki besin elementleri arasındaki dengenin korunmasına da yardım ettiği bilinmektedir. Verimliliğin artırılmasında kimyasal gübrelerle beraber organik gübrelerinde birlikte kullanılması en etkili yöntemdir. Yetiştiricilikte verim ve kalitenin artmasında organik gübrelerin rekabeti önemlidir. Özellikle de sebze yetiştiriciliğinde bitkilerin tercih ettikleri en ideal topraklar organik maddece zengin topraklardır.

Topraklara ilave edilen organik gübreler alınabilir formda azot içermelerinden dolayı bitki gelişimini artırarak bitkilerde toprak üstü kısımları oluştururlar ve topraklarda organik madde miktarının artmasını sağlarlar (Akalan 1987; Haynes ve Naidu 1998). Tarımda başarılı bir üretim için toprak organik madde miktarını korumak ve artırmak gerekmektedir. $\mathrm{Bu}$ nedenle organik materyallerin uygun bir şekilde olgunlaştırılarak topraklara kazandırılmaları gerekmektedir (Kacar ve Katkat 2007).

$\mathrm{Bu}$ çalışma, farklı organik materyallerin artan dozlarının marul yetiştirilen toprakların bazı verimlilik parametreleri üzerine olan etkilerinin belirlenmesi amacıyla yapılmıştır.

\section{Materyal ve Yöntem}

Araştırma farklı organik gübrelerin ve dozlarının marul yetiştiriciliği üzerine olan etkilerini belirlemek amaciyla Akdeniz Üniversitesi Ziraat Fakültesi'ne ait araştırma seralarında yürütülmüştür. Denemede Presidential Yedikule marul çeşidi kullanılmıştır. Araştırmada Çizelge 1'de özellikleri verilen toprağa organik gübre olarak çiftlik gübresi $\left(100 \mathrm{~kg} \mathrm{da}^{-1}\right.$, $\left.200 \mathrm{~kg} \mathrm{da}^{-1}, 300 \mathrm{~kg} \mathrm{da}^{-1}\right)$, tavuk gübresi $\left(100 \mathrm{~kg} \mathrm{da}^{-1}, 200 \mathrm{~kg} \mathrm{da}^{-}\right.$ 1, $\left.300 \mathrm{~kg} \mathrm{da}^{-1}\right)$, leonardit $\left(50 \mathrm{~kg} \mathrm{da}^{-1}, 100 \mathrm{~kg} \mathrm{da}^{-1}, 150 \mathrm{~kg} \mathrm{da}^{-1}\right) \mathrm{ve}$ vermikompost (100 kg da-1, $\left.200 \mathrm{~kg} \mathrm{da}^{-1}, 300 \mathrm{~kg} \mathrm{da}^{-1}\right)$ uygulanmıştır. Ayrıca organik gübre uygulanmayan bir konuda kontrol olarak denemede yer almıştır. Denemede kullanılan tüm organik gübreler ticari firmalardan temin edilmiş olup, organik gübrelere ait ticari firmalar tarafindan beyan edilen analiz sonuçları Çizelge 2'de verilmiştir.

Araştırma 4'er tekerrürlü olarak faktöriyel deneme desenine göre planlanmıştır. Deneme toprağına organik gübreler önerilen dozlarda uygulanmış ve 30 gün boyunca inkübasyona tabii tutulmuştur. 5 kg'lık saksılara 21 Eylül 2016 tarihinde dikim yapılmış, dikimden sonraki bütün kültürel işlemler (sulama, ilaçlama vb.) tüm uygulama parsellerine eşit uygulanmıştır. Denemede organik materyallere ilave olarak her uygulamaya 10 $\mathrm{kg} \mathrm{da} \mathrm{d}^{-1} \mathrm{~N}, 5 \mathrm{~kg} \mathrm{da}^{-1} \mathrm{P}, 20 \mathrm{~kg} \mathrm{da}^{-1} \mathrm{~K}$ olacak şekilde kimyasal gübreleme yapılmış ve deneme 15 Aralık 2016 tarihinde sonlandırılmıştır.

Toprak örneklerinin pH'ları Jackson'a göre 1/2.5 toprak/su karışımında (Jackson 1967), $\mathrm{CaCO}_{3}$ içerikleri Scheibler kalsimetresi kullanılarak (Evliya 1964), elektriksel iletkenlik saturasyon çamurunda (Anonim 1988), bünye; Bouyoucos hidrometre yöntemine göre (Bouyoucos 1955), organik madde modifiye Walkey-Black metoduna göre (Black 1965) belirlenmiştir. Toplam N modifiye Kjeldahl metoduna göre (Black 1957), alınabilir P, Olsen metoduna göre (Olsen 1982), ekstrakte edilebilir $\mathrm{K}, \mathrm{Ca}$ ve $\mathrm{Mg}$ analizleri $1 \mathrm{~N}$ Amonyum Asetat $(\mathrm{pH}=7)$ metoduna göre (Kacar 1972) ve alınabilir Fe, $\mathrm{Zn}, \mathrm{Cu}$ ve $\mathrm{Mn}$ analizleri ise DTPA metoduna göre (Lindsay ve Norwell 1978) yapılmıştır. Laboratuvar analizleri ve ölçümler neticesinde elde edilen veriler SAS istatistik programında analizi yapılarak yetiştirme ortamları arasındaki farklılıklar belirlenmiştir. Ortalamalar DUNCAN çoklu karşıllaştırma testi ile karşılaştırılmıştır.

Çizelge 1. Araştırmada kullanılan deneme toprağının bazı fiziksel ve kimyasal özellikleri.

Table 1. Some physical and chemical properties of soil used in study.

\begin{tabular}{|c|c|c|}
\hline Toprak Özelliği & Değer & Değerlendirme \\
\hline Bünye & - & Killi \\
\hline $\mathrm{pH}$ & 7.33 & Nötr \\
\hline $\mathrm{EC}\left(\mathrm{dS} \mathrm{m} \mathrm{m}^{-1}\right)$ & 0.29 & Tuzsuz \\
\hline Organik Madde (\%) & 2.03 & Az Humuslu \\
\hline Kireç $\left(\% \mathrm{CaCO}_{3}\right)$ & 12.56 & Çok Yüksek \\
\hline Toplam N (\%) & 0.159 & Çok İyi \\
\hline Alınabilir P (mg kg-1) & 17.56 & Yüksek \\
\hline Değişebilir K (me $100 \mathrm{~g}^{-1}$ ) & 0.68 & Yüksek \\
\hline Değişebilir Mg (me $\left.100 \mathrm{~g}^{-1}\right)$ & 1.26 & İyi \\
\hline Değişebilir Ca (me $\left.100 \mathrm{~g}^{-1}\right)$ & 12.65 & Orta \\
\hline Alınabilir Fe $\left(\mathrm{mg} \mathrm{kg}^{-1}\right)$ & 4.13 & Noksanlık Gösterebilir \\
\hline Alınabilir Zn (mg kg-1) & 4.14 & İyi \\
\hline Alınabilir Mn (mg kg $\left.{ }^{-1}\right)$ & 5.25 & Yeterli \\
\hline Alınabilir $\mathrm{Cu}\left(\mathrm{mg} \mathrm{kg}^{-1}\right)$ & 2.07 & Yeterli \\
\hline
\end{tabular}

Çizelge 2. Denemede kullanılan organik gübrelerin bazı kimyasal özellikleri.

Table 2. Properties of organic manures used in the study.

\begin{tabular}{lcccc}
\hline & $\begin{array}{c}\text { Tavuk } \\
\text { Gübresi } \\
\text { Özellikler }\end{array}$ & $\begin{array}{c}\text { Çiftlik } \\
\text { Gübresi } \\
(\text { ÇG })\end{array}$ & $\begin{array}{c}\text { Leonardit } \\
(\mathrm{L})\end{array}$ & $\begin{array}{c}\text { Vermikompost } \\
(\mathrm{V})\end{array}$ \\
\hline $\mathrm{N}(\%)$ & 2.11 & 1.33 & 0.80 & 1.38 \\
$\mathrm{P}(\%)$ & 0.89 & 0.06 & 0.01 & 0.09 \\
$\mathrm{~K}(\%)$ & 1.15 & 0.16 & 0.02 & 0.15 \\
$\mathrm{Ca}(\%)$ & 5.60 & 1.05 & 3.06 & 0.68 \\
$\mathrm{Mg}(\%)$ & 0.36 & 0.10 & 0.08 & 0.09 \\
Fe mg kg-1 & 1146 & 1499 & 1904 & 851 \\
$\mathrm{Mn} \mathrm{mg} \mathrm{kg}{ }^{-1}$ & 162 & 45.2 & 19.6 & 42.4 \\
$\mathrm{Zn} \mathrm{mg} \mathrm{kg}$ & 150 & 8.3 & 0.7 & 10.5 \\
$\mathrm{Cu} \mathrm{mg} \mathrm{kg}$ & 22.5 & 2.4 & 1.5 & 2.9 \\
pH & 9.36 & 7.50 & 6.98 & 7.28 \\
EC $\left(\mathrm{dS} \mathrm{m}{ }^{-1}\right)$ & 23.3 & 10.6 & 2.86 & 12.2 \\
O.M. $(\%)$ & 40 & 40 & 35 & 40 \\
\hline
\end{tabular}

\section{Bulgular ve Tartış̧ma}

Farklı organik materyallerin ve artan dozlarının bazı toprak özellikleri üzerine olan etkilerinin belirlenmeye çalışıldığı bu araştırmada; gübre, doz ve gübre $\mathrm{x} \mathrm{doz}$ interaksiyonlarının etkileri ve önem dereceleri çizelgelerde verilmiştir. Çizelge 3'den görüleceği üzere TG ve L en yüksek $\mathrm{pH}$ değerlerinin elde edildiği organik materyaller olarak belirlenirken interaksiyonda farklılıklar oluşmaktadır. Genel olarak doz artışıla $\mathrm{pH}$ değerlerinde düşüş görülmektedir. Literatür bilgileri bu sonucu doğrulamaktadır (Kütük ve ark. 1999; Sharif ve ark. 2004; Doğan 2000). Toprakların EC değerleri üzerine organik materyal ve dozlarının etkileri değerlendirildiğinde gübreler içerisinde TG en yüksek EC değerlerinin oluşumuna neden olurken 2. ve 3 . dozlarda en yüksek doz değerlerini 
sağlamışlardır. Bilindiği üzere organik gübreler toprakların EC değerlerinin artışına neden olabilmektedir. Yapılan bazı çalışmalarda organik gübre uygulamalarının toprakların EC değerlerini artırdığ 1 bildirilmiştir (Kütük ve ark. 2003; Aydınşakir ve ark. 2011; Çıtak ve ark. 2011). Ancak bu çalışmada elde edilen EC değerlerinin tuzluluk riski oluşturabilecek düzeylerde olmadığı görülmüştür(Çizelge 3).

Deneme topraklarının organik madde içerikleri üzerine organik gübrelerin ve dozların etkisi istatistiksel olarak önemli bulunmuş, L ve ÇG uygulamaları ve 3.uygulama dozu en yüksek değerlerin elde edildiği uygulamalar olarak belirlenmişlerdir(Çizelge 4). Toprağa ilave edilen organik gübreler toprakların organik madde içeriklerinde artışa neden olmaktadır (Alagöz ve ark. 2006; Ece ve ark. 2007; Çıtak ve ark. 2011). Toprakların azot içerikleri üzerine organik gübrelerin, dozlarının ve gübre $\mathrm{x}$ doz interaksiyonunun etkileri istatistiksel olarak önemli bulunmuş, gübrelerde TG uygulamas1, dozlarda 3.doz ve interaksiyonda TG2 ve TG3 en yüksek değerlerin elde edildiği uygulamalar olmuştur (Çizelge 4). Toprakların azot içeriklerinin artışında tavuk gübresinin artan dozlarının etkileri önemli katkılar sağlamaktadır (Alagöz ve ark. 2006; Okur ve ark. 2008).

Toprakların alınabilir fosfor içeriklerinde ise gübrelerde ÇG uygulamas1, dozlarda 2.ve 3.dozlar, interaksiyonda ise ÇG2 uygulaması en yüksek değerleri sağlamışlardır(Çizelge 5). Toprakların alınabilir fosfor kapsamına ÇG uygulamalarının etkisi daha fazla gerçekleşmiştir (Agbenin ve Goladi 1997). Değişebilir potasyum içeriklerinde gübre uygulamalarında ÇG, dozlarda 3. doz ve interaksiyonda ÇG2-ÇG3 en yüksek değerlerin elde edildiği uygulamalar olmuştur. Organik gübrelerin toprakların değişebilir potasyum değerleri üzerine önemli etkileri bulunmaktadır(Asri 2011). Toprakların değişebilir kalsiyum içerikleri üzerine gübre uygulamalarında ÇG uygulaması, dozlarda kontrol hariç tüm dozlar etkili olurken GxD interaksiyonunda ÇG3 uygulaması en yüksek kalsiyum değerini sağlamıştır. Organik gübre uygulamalarının toprakların değişebilir kalsiyum içeriklerine katk1 sağladığ araştırmacı tarafından belirtilmektedir (Lopez ve ark. 2004; Vavoulidou ve ark. 2004; Azarmi ve ark. 2008). Araştırmada toprakların değişebilir magnezyum içeriklerine organik gübre ve dozlarının etkileri istatistiksel olarak önemli bulunmamıştır(Çizelge 6).

Organik materyaller ve farklı dozlarının toprakların mikroelement içerikleri üzerine olan etkileri incelendiğinde; toprakların alınabilir demir içerikleri üzerine gübre etkisi istatistiksel olarak önemli bulunmazken doz etkisinde kontrol hariç tüm dozların olumlu etkileri belirlenmiştir. Alınabilir çinko ve bakır içeriklerinde ise ÇG uygulaması en yüksek değerlerin elde edildiği organik gübre olarak belirlenmiştir. Alınabilir mangan içeriklerinde doz etkisi bakımından kontrol ve 1. doz öne çıkarken gübre etkisi istatistiksel olarak önemli bulunmamıştır (Çizelge 7 ve 8). Organik materyal uygulamalarının toprakların mikroelement içeriği üzerine olumlu etkileri bulunmaktadır(Walter ve ark. 2006; Asri ve ark. 2011).

Çizelge 3. Farklı organik gübrelerin ve uygulama dozlarının toprakların pH ve EC değerleri üzerine etkisi ${ }^{1}$.

Table 3. The effect of different organic manures and its application doses on $\mathrm{pH}$ and $\mathrm{EC}$ values of soils ${ }^{1}$.

\begin{tabular}{|c|c|c|c|c|c|c|c|c|c|c|}
\hline \multirow{3}{*}{$\begin{array}{l}\text { Organik } \\
\text { Gübreler }\end{array}$} & \multicolumn{5}{|c|}{$\mathrm{pH}$} & \multicolumn{5}{|c|}{ EC } \\
\hline & \multicolumn{5}{|c|}{ Dozlar } & \multicolumn{5}{|c|}{ Dozlar } \\
\hline & 0 & 1 & 2 & 3 & Ort. & 0 & 1 & 2 & 3 & Ort. \\
\hline TG & $7.18 \mathrm{a}^{2}$ & $7.22 \mathrm{a}$ & $7.22 \mathrm{a}$ & $7.18 \mathrm{a}$ & $7.20 \mathrm{~A}$ & $0.335^{2}$ & 0.359 & 0.421 & 0.488 & $0.401 \mathrm{~A}$ \\
\hline V & $7.18 \mathrm{a}$ & 7.15ab & $7.01 \mathrm{c}$ & $7.07 \mathrm{bc}$ & 7.10B & 0.335 & 0.327 & 0.361 & 0.365 & $0.347 \mathrm{~B}$ \\
\hline $\mathrm{L}$ & $7.18 \mathrm{a}$ & $7.26 \mathrm{a}$ & $7.24 \mathrm{a}$ & $7.21 \mathrm{a}$ & $7.22 \mathrm{~A}$ & 0.335 & 0.352 & 0.371 & 0.411 & $0.367 \mathrm{~B}$ \\
\hline ÇG & $7.18 \mathrm{a}$ & $7.05 b c$ & 7.04 & $7.07 \mathrm{ba}$ & 7.09B & 0.335 & 0.339 & 0.362 & 0.378 & 0.354B \\
\hline Ort. & $7.18 \mathrm{a}$ & 7.17 & 7.13 & 7.13 & - & $0.335(\mathrm{~B})$ & $0.344(\mathrm{~B})$ & $0.379(\mathrm{~A})$ & $0.410(\mathrm{~A})$ & - \\
\hline Gübre $(G)^{2}$ & \multicolumn{5}{|c|}{$15.84 * * *$} & \multicolumn{5}{|c|}{$4.35 * *$} \\
\hline Doz (D) & \multicolumn{5}{|c|}{ 2.62öd } & \multicolumn{5}{|c|}{$9.01 * * *$} \\
\hline GxD & \multicolumn{5}{|c|}{$2.58^{*}$} & \multicolumn{5}{|c|}{ 1.12öd } \\
\hline
\end{tabular}

${ }^{1}$ Değerler 4 tekerrür ortalamasıdır. ${ }^{2} \mathrm{~F}$ değerleri esas alınmıștır. *: \%5 düzeyinde önemli, **: \%1 düzeyinde önemli, ***: \%0.1 düzeyinde önemli, öd: önemli değil. Ayn harfle gösterilmeyen değerler arasındaki farklar $p<0.05$ düzeyinde önemlidir. Büyük harfle gösterilen değerler organik gübre uygulamaları arasındaki farklılığ 1 göstermektedir. Parantez içerisinde büyük harfle gösterilen değerler farklı dozlar arasındaki farklılığı göstermektedir.

Çizelge 4. Farklı organik gübrelerin ve uygulama dozlarının toprakların organik madde (\%) ve toplam azot (\%) değerleri üzerine etkisi ${ }^{1}$. Table 4. The effect of different organic manures and its application doses on organic matter content (\%) and total nitrogen (\%) of soils ${ }^{1}$.

\begin{tabular}{|c|c|c|c|c|c|c|c|c|c|c|}
\hline \multirow{3}{*}{$\begin{array}{l}\text { Organik } \\
\text { Gübreler }\end{array}$} & \multicolumn{5}{|c|}{ Organik Madde (\%) } & \multicolumn{5}{|c|}{$\mathrm{N}(\%)$} \\
\hline & \multicolumn{5}{|c|}{ Dozlar } & \multicolumn{5}{|c|}{ Dozlar } \\
\hline & 0 & 1 & 2 & 3 & Ort. & 0 & 1 & 2 & 3 & Ort. \\
\hline TG & $2.03^{2}$ & 2.12 & 2.20 & 2.34 & 2.17 & $0.131 \mathrm{f}^{2}$ & $0.183 b c$ & $0.195 \mathrm{a}$ & $0.202 \mathrm{a}$ & $0.178 \mathrm{~A}$ \\
\hline V & 2.03 & 2.16 & 2.27 & 2.31 & 2.19 & $0.131 \mathrm{f}$ & $0.155 \mathrm{e}$ & $0.161 \mathrm{e}$ & $0.178 \mathrm{c}$ & $0.156 \mathrm{C}$ \\
\hline $\mathrm{L}$ & 2.03 & 2.50 & 2.43 & 2.55 & 2.38 & $0.131 \mathrm{f}$ & $0.161 \mathrm{e}$ & $0.174 \mathrm{~cd}$ & $0.177 \mathrm{~cd}$ & $0.161 \mathrm{C}$ \\
\hline ÇG & 2.03 & 2.32 & 2.42 & 2.55 & 2.33 & $0.131 \mathrm{f}$ & $0.166 \mathrm{de}$ & $0.179 \mathrm{c}$ & $0.193 \mathrm{ab}$ & $0.167 \mathrm{~B}$ \\
\hline Ort. & $2.03 \mathrm{C}$ & $2.27 \mathrm{~B}$ & $2.33 \mathrm{AB}$ & $2.44 \mathrm{~A}$ & - & $0.131(\mathrm{D})$ & $0.166(\mathrm{C})$ & $0.177(\mathrm{~B})$ & $0.187(\mathrm{~A})$ & - \\
\hline Gübre $(G)^{2}$ & \multicolumn{5}{|c|}{$5.21 * *$} & \multicolumn{5}{|c|}{$25.22 * * *$} \\
\hline Doz (D) & \multicolumn{5}{|c|}{$15.56 * * *$} & \multicolumn{5}{|c|}{$172.68 * * *$} \\
\hline GxD & \multicolumn{5}{|c|}{0.81 öd } & \multicolumn{5}{|c|}{$3.44 * *$} \\
\hline
\end{tabular}

${ }^{1}$ Değerler 4 tekerrür ortalamasıdır. ${ }^{2} \mathrm{~F}$ değerleri esas alınmıştır. $* *: \% 1$ düzeyinde önemli, ***: \%0.1 düzeyinde önemli, öd: önemli değil. Aynı harfle gösterilmeyen değerler arasındaki farklar $p<0.05$ düzeyinde önemlidir. Büyük harfle gösterilen değerler organik gübre uygulamaları arasındaki farklılığı göstermektedir. Parantez içerisinde büyük harfle gösterilen değerler farklı dozlar arasındaki farklılığı göstermektedir. 


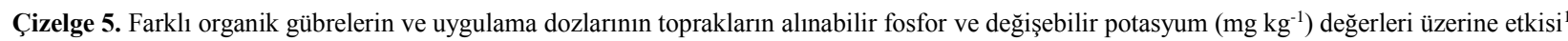
Table 5. The effect of different organic manures and its application doses on phosphorus and potassium content $\left(\mathrm{mg} \mathrm{kg}^{-1}\right)$ of soils ${ }^{1}$.

\begin{tabular}{|c|c|c|c|c|c|c|c|c|c|c|}
\hline \multirow{3}{*}{$\begin{array}{l}\text { Organik } \\
\text { Gübreler }\end{array}$} & \multicolumn{5}{|c|}{$\mathrm{P}\left(\mathrm{mg} \mathrm{kg}^{-1}\right)$} & \multicolumn{5}{|c|}{$\mathrm{K}\left(\mathrm{mg} \mathrm{kg}^{-1}\right)$} \\
\hline & \multicolumn{5}{|c|}{ Dozlar } & \multicolumn{5}{|c|}{ Dozlar } \\
\hline & 0 & 1 & 2 & 3 & Ort. & 0 & 1 & 2 & 3 & Ort. \\
\hline TG & $19.3 \mathrm{de}^{2}$ & 20.4 cde & $27.1 \mathrm{bc}$ & $28.1 \mathrm{~b}$ & $23.7 \mathrm{~B}$ & $273.7 \mathrm{bcd}$ & $252.9 \mathrm{cdef}$ & 249.6def & $367.2 \mathrm{bcde}$ & $260.8 \mathrm{C}$ \\
\hline V & $19.3 \mathrm{de}$ & $23.4 \mathrm{bcde}$ & 22.5 bcde & $18.9 \mathrm{de}$ & $21.0 \mathrm{BC}$ & $273.7 \mathrm{bcd}$ & $233.5 f$ & $238.1 \mathrm{ef}$ & $274.1 \mathrm{bcd}$ & $254.8 \mathrm{C}$ \\
\hline $\mathrm{L}$ & 19.3de & $19.8 \mathrm{cde}$ & $17.3 \mathrm{e}$ & 21.9 bcde & $19.6 \mathrm{C}$ & $273.7 \mathrm{bcd}$ & $296.8 b$ & $281.9 \mathrm{bcd}$ & $276.9 \mathrm{bcd}$ & 282.3B \\
\hline ÇG & $19.3 \mathrm{de}$ & $25.9 \mathrm{bcd}$ & $35.7 \mathrm{a}$ & $27.9 \mathrm{~b}$ & $27.2 \mathrm{~A}$ & $273.7 \mathrm{bcd}$ & $283.6 b c$ & $334.6 \mathrm{a}$ & $344.5 \mathrm{a}$ & $309.1 \mathrm{~A}$ \\
\hline Ort. & $19.3(\mathrm{~B})$ & $22.4(\mathrm{AB})$ & $25.6(\mathrm{~A})$ & 24.2(A) & - & 273.7(B) & 266.7(B) & $276.0(\mathrm{~B})$ & $290.7(\mathrm{~A})$ & - \\
\hline Gübre $(\mathrm{G})^{2}$ & \multicolumn{5}{|c|}{$8.71 * * *$} & \multicolumn{5}{|c|}{$24.37 * * *$} \\
\hline $\operatorname{Doz}(\mathrm{D})$ & \multicolumn{5}{|c|}{$5.87 * *$} & \multicolumn{5}{|c|}{$4.12 *$} \\
\hline GxD & \multicolumn{5}{|c|}{$2.88 * *$} & \multicolumn{5}{|c|}{$5.34 * * *$} \\
\hline
\end{tabular}

${ }^{1}$ Değerler 4 tekerrür ortalamasıdır. ${ }^{2} \mathrm{~F}$ değerleri esas alınmıştır. *: \%5 düzeyinde önemli, **: \%1 düzeyinde önemli, ***: \%0.1 düzeyinde önemli, Aynı harfle gösterilmeyen değerler arasındaki farklar $p<0.05$ düzeyinde önemlidir. Büyük harfle gösterilen değerler organik gübre uygulamaları arasındaki farklılığı göstermektedir. Parantez içerisinde büyük harfle gösterilen değerler farklı dozlar arasındaki farklılığı göstermektedir.

Çizelge 6. Farklı organik gübrelerin ve uygulama dozlarının toprakların değişebilir kalsiyum ve magnezyum $\left(\mathrm{mg} \mathrm{kg}^{-1}\right)$ değerleri üzerine etkisi ${ }^{1}$.

Table 6. The effect of different organic manures and its application doses on calcium and magnesium content $\left(\mathrm{mg} \mathrm{kg}^{-1}\right)$ of soils ${ }^{1}$.

\begin{tabular}{|c|c|c|c|c|c|c|c|c|c|c|}
\hline \multirow{3}{*}{$\begin{array}{l}\text { Organik } \\
\text { Gübreler }\end{array}$} & \multicolumn{5}{|c|}{$\mathrm{Ca}\left(\mathrm{mg} \mathrm{kg}^{-1}\right)$} & \multicolumn{5}{|c|}{$\mathrm{Mg}\left(\mathrm{mg} \mathrm{kg}^{-1}\right)$} \\
\hline & \multicolumn{5}{|c|}{ Dozlar } & \multicolumn{5}{|c|}{ Dozlar } \\
\hline & 0 & 1 & 2 & 3 & Ort. & 0 & 1 & 2 & 3 & Ort. \\
\hline TG & $2529.8 \mathrm{~cd}^{2}$ & $2571.8 \mathrm{~cd}$ & $2633.5 b c$ & $2760.3 \mathrm{ab}$ & $2623.8 \mathrm{~B}$ & 165.28 & 162.75 & 161.73 & 182.08 & 167.96 \\
\hline $\mathrm{V}$ & $2529.8 \mathrm{~cd}$ & $2781.0 \mathrm{ab}$ & $2779.8 \mathrm{ab}$ & $2405.3 d$ & $2623.9 \mathrm{~B}$ & 165.28 & 172.93 & 166.85 & 156.40 & 165.36 \\
\hline $\mathrm{L}$ & $2529.8 \mathrm{~cd}$ & $2667.3 b c$ & $2694.3 \mathrm{abc}$ & $2715.5 \mathrm{abc}$ & $2651.7 \mathrm{AB}$ & 165.28 & 163.98 & 165.95 & 153.35 & 162.14 \\
\hline ÇG & $2529.8 \mathrm{~cd}$ & $2757.8 \mathrm{ab}$ & $2764.3 \mathrm{ab}$ & $2862.8 \mathrm{a}$ & $2728.6 \mathrm{~A}$ & 165.28 & 175.50 & 168.63 & 170.95 & 170.09 \\
\hline Ort. & $2529.8(\mathrm{~B})$ & 2694.4(a) & 2717.9(A) & $2685.9(\mathrm{~A})$ & - & 165.28 & 168.79 & 165.79 & 165.69 & - \\
\hline Gübre $(\mathrm{G})^{2}$ & \multicolumn{5}{|c|}{$3.05^{*}$} & \multicolumn{5}{|c|}{0.82 öd } \\
\hline Doz (D) & \multicolumn{5}{|c|}{$9.19 * * *$} & \multicolumn{5}{|c|}{0.18 öd } \\
\hline GxD & \multicolumn{5}{|c|}{$4.43^{* * *}$} & \multicolumn{5}{|c|}{$1.05 \mathrm{öd}$} \\
\hline
\end{tabular}

${ }^{1}$ Değerler 4 tekerrür ortalamasıdır. ${ }^{2} \mathrm{~F}$ değerleri esas alınmıștır. *: \%5 düzeyinde önemli, ***: \%0.1 düzeyinde önemli, öd: önemli değil. Aynı harfle gösterilmeyen değerler arasındaki farklar $p<0.05$ düzeyinde önemlidir. Büyük harfle gösterilen değerler organik gübre uygulamaları arasındaki farklıllğı göstermektedir. Parantez içerisinde büyük harfle gösterilen değerler farklı dozlar arasındaki farklılı̆ğ göstermektedir.

Çizelge 7. Farklı organik gübrelerin ve uygulama dozlarının toprakların alınabilir demir ve çinko $\left(\mathrm{mg} \mathrm{kg}^{-1}\right)$ değerleri üzerine etkisi ${ }^{1}$.

Table 7. The effect of different organic manures and its application doses on iron and zinc content $\left(\mathrm{mg} \mathrm{kg}^{-1}\right)$ of soils ${ }^{1}$.

\begin{tabular}{|c|c|c|c|c|c|c|c|c|c|c|}
\hline \multirow{3}{*}{$\begin{array}{l}\text { Organik } \\
\text { Gübreler }\end{array}$} & \multicolumn{5}{|c|}{$\mathrm{Fe}\left(\mathrm{mg} \mathrm{kg}^{-1}\right)$} & \multicolumn{5}{|c|}{$\mathrm{Zn}\left(\mathrm{mg} \mathrm{kg}^{-1}\right)$} \\
\hline & \multicolumn{5}{|c|}{ Dozlar } & \multicolumn{5}{|c|}{ Dozlar } \\
\hline & 0 & 1 & 2 & 3 & Ort. & 0 & 1 & 2 & 3 & Ort. \\
\hline TG & $4.38^{2}$ & 4.58 & 4.63 & 4.65 & 4.56 & 1.59 & 1.86 & 1.43 & 1.80 & $1.67 \mathrm{~A}$ \\
\hline V & 4.38 & 4.75 & 4.69 & 4.83 & 4.66 & 1.59 & 1.26 & 1.62 & 1.25 & $1.43 \mathrm{~B}$ \\
\hline $\mathrm{L}$ & 4.38 & 4.67 & 4.66 & 4.88 & 4.65 & 1.59 & 1.59 & 1.46 & 1.62 & $1.57 \mathrm{AB}$ \\
\hline ÇG & 4.38 & 4.67 & 4.93 & 4.99 & 4.74 & 1.59 & 1.67 & 1.64 & 1.56 & $1.61 \mathrm{~A}$ \\
\hline Ort. & 4.38B & $4.67 \mathrm{~A}$ & $4.73 \mathrm{~A}$ & $4.84 \mathrm{~A}$ & - & 1.59 & 1.59 & 1.54 & 1.56 & - \\
\hline Gübre $(G)^{2}$ & \multicolumn{5}{|c|}{ 0.78öd } & \multicolumn{5}{|c|}{$2.99 *$} \\
\hline $\operatorname{Doz}(\mathrm{D})$ & \multicolumn{5}{|c|}{$5.32 * *$} & \multicolumn{5}{|c|}{0.21 öd } \\
\hline GxD & \multicolumn{5}{|c|}{0.24 öd } & \multicolumn{5}{|c|}{ 1.98öd } \\
\hline
\end{tabular}

${ }^{1}$ Değerler 4 tekerrür ortalamasıdır. ${ }^{2} \mathrm{~F}$ değerleri esas alınmıştır. *: \%5 düzeyinde önemli, **: \%1 düzeyinde önemli, öd: önemli değil. Aynı harfle gösterilmeyen değerler arasındaki farklar $p<0.05$ düzeyinde önemlidir. Büyük harfle gösterilen değerler organik gübre uygulamaları arasındaki farklıllğı göstermektedir. Parantez içerisinde büyük harfle gösterilen değerler farklı dozlar arasındaki farklılı̆̆ı göstermektedir. 
Çizelge 8. Farklı organik gübrelerin ve uygulama dozlarının toprakların alınabilir mangan ve bakır $\left(\mathrm{mg} \mathrm{kg}^{-1}\right)$ değerleri üzerine etkisi ${ }^{1}$. Table 8. The effect of different organic manures and its application doses on manganese and copper content (mg kg-1) of soils ${ }^{1}$.

\begin{tabular}{|c|c|c|c|c|c|c|c|c|c|c|}
\hline \multirow{3}{*}{$\begin{array}{l}\text { Organik } \\
\text { Gübreler }\end{array}$} & \multicolumn{5}{|c|}{$\operatorname{Mn}\left(\mathrm{mg} \mathrm{kg}^{-1}\right)$} & \multicolumn{5}{|c|}{$\mathrm{Cu} \quad\left(\mathrm{mg} \mathrm{kg}^{-1}\right)$} \\
\hline & \multicolumn{5}{|c|}{ Dozlar } & \multicolumn{5}{|c|}{ Dozlar } \\
\hline & 0 & 1 & 2 & 3 & Ort. & 0 & 1 & 2 & 3 & Ort. \\
\hline TG & 5.77 & 6.06 & 5.15 & 5.16 & 5.53 & 1.050 & 1.030 & 0.763 & 0.788 & $0.908 \mathrm{~B}$ \\
\hline V & 5.77 & 5.21 & 5.46 & 5.18 & 5.40 & 1.050 & 0.928 & 1.038 & 1.035 & $1.013 \mathrm{AB}$ \\
\hline $\mathrm{L}$ & 5.77 & 5.55 & 5.20 & 5.33 & 5.46 & 1.050 & 0.953 & 1.018 & 1.035 & $1.014 \mathrm{AB}$ \\
\hline ÇG & 5.77 & 6.38 & 5.56 & 5.18 & 5.72 & 1.050 & 1.250 & 1.175 & 1.083 & $1.139 \mathrm{~A}$ \\
\hline Ort. & 5.77(A) & $5.80(\mathrm{~A})$ & 5.34(B) & $5.21(\mathrm{~B})$ & - & 1.050 & 1.040 & 0.998 & 0.985 & - \\
\hline Gübre $(G)^{2}$ & \multicolumn{5}{|c|}{ 1.15öd } & \multicolumn{5}{|c|}{$4.57 * *$} \\
\hline Doz (D) & \multicolumn{5}{|c|}{$5.30 * *$} & \multicolumn{5}{|c|}{0.51 öd } \\
\hline GxD & \multicolumn{5}{|c|}{$1.21 \mathrm{od}$} & \multicolumn{5}{|c|}{$1.39 \mathrm{od}$} \\
\hline
\end{tabular}

${ }^{1}$ Değerler 4 tekerrür ortalamasıdır. ${ }^{2} \mathrm{~F}$ değerleri esas alınmıştır. **: \%1 düzeyinde önemli, öd: önemli değil. Aynı harfle gösterilmeyen değerler arasındaki farklar $p<0.05$ düzeyinde önemlidir. Büyük harfle gösterilen değerler organik gübre uygulamaları arasındaki farklılı̆̆ göstermektedir. Parantez içerisinde büyük harfle gösterilen değerler farklı dozlar arasındaki farklılı̆̆ göstermektedir.

\section{Sonuçlar}

Tarımsal üretimde verim ve kalitenin arttırılmasında gübreleme uygulamaları oldukça önemli bir role sahiptir. Gübreleme; yetiştirilecek bitki çeşidine göre farklılık göstermekle birlikte ekolojik faktörlere, toprak faktörlerine ve gübrelerin üretim yöntemlerine göre de farklılık gösterebilmektedir. Tarımda gübreleme ile verimlilik arasında sıkı bir ilişki olduğu bilinmektedir. Bitkisel üretimde, hedeflenen verimin ve kalitenin sağlanabilmesi için organik ve inorganik kaynaklardan yararlanılmak zorundadır. Ülkemiz topraklarının organik madde kapsamı yetersizdir ve toprağa uygulanan organik materyaller toprağın fiziksel ve kimyasal özellikleri üzerine olumlu etkiler göstermektedir. Organik materyal ilavesiyle toprakların verimlilik parametreleri iyileşerek elde edilecek ürünlerde kalite ve verim unsurları daha yüksek potansiyel oluşturabilecektir.

Farklı organik gübrelerin toprak özelliklerinde $\mathrm{pH}, \mathrm{EC}$, organik madde, $\mathrm{N}, \mathrm{P}, \mathrm{K}, \mathrm{Ca}, \mathrm{Zn}$ ve $\mathrm{Cu}$ içeriklerinde etkili olurken tavuk gübresi ve çiftlik gübresinin bu parametrelerde en etkili gübreler olduğu belirlenmiştir. Uygulama dozları bakımından yapılan değerlendirmede ise $\mathrm{EC}$, organik madde, $\mathrm{N}$, $\mathrm{P}, \mathrm{K}, \mathrm{Ca}, \mathrm{Fe}$ ve $\mathrm{Mn}$ içeriklerinde doz etkileri önemli olarak belirlenmiş ve genel olarak 2. ve 3 . dozlar öne çıkmıştır. Organik gübreler ile uygulama dozları arasındaki ilişki bakımından ise tavuk gübresi ve çiftlik gübresinin 2 . ve 3 . dozları daha etkili olmuşlardır. Organik materyal ilavesi toprak verimliliğini ve bitki besleme etkinliğini artırarak toprakların sürdürülebilirliği açısından önemli avantajlar sağlayabilmektedir.

\section{Kaynaklar}

Agbenin JO, Goladi JT (1997) Carbon, nitrogen and phosphorus dynamics under continuous cultivation as influenced by farmyard manure and inorganic fertilizers in the savanna of northern Nigeria. Agriculture, Ecosystems and Environment 63: 17-24.

Akalan İ (1987) Organik Madde Kaynakları. Toprak Bilgisi Ankara Üniversitesi Ziraat Fakültesi Yayınları Ders Kitabı: 309, Ankara, s. 218-219.

Alagöz Z, Yılmaz E, Öktüren F (2006) Organik materyal ilavesinin bazı fiziksel ve kimyasal toprak özellikleri üzerine etkileri. Akdeniz Üniversitesi Ziraat Fakültesi Dergisi 19(2): 245-254.

Anonim (1988) Meyve, sebze ve mamulleri- nitrit ve nitrat tayinimoleküler absorpsiyon spektrofotometrik metot. Türk Standard,, ICS 67.080, TS 6183/Aralık 1988.
Asri FÖ, Demirtaş EI, Özkan CF, Arı N (2011) Organik ve kimyasal gübre uygulamalarının hıyar bitkisinin verim, kalite ve mineral içeriklerine etkileri. Akdeniz Üniversitesi Ziraat Fakültesi Dergisi 24(2): 139-143.

Aydınşakir K, Ünlü A, Yılmaz S, Arı N (2011) Kentsel katı atık kompost uygulamalarının toprak özellikleri ve düğün çiçeği (Ranunculus Asiaticus 'Orange')'nin verim ve kalitesi üzerine etkileri. Akdeniz Üniversitesi Ziraat Fakültesi Dergisi 24(1): 55-60.

Azarmi R, Giglou MT, Talesmikail RD (2008) Influence of vermicompost on soil chemical and physical properties in tomato (Lycopersicum Esculentum) Field. African Journal of Biotechnology 7(14): 2397-2401.

Black CA (1957) Soil-plant relationships. John Wiley and Sons, Inc., New York.

Black CA (1965) Methods of soil analysis Part 2, Amer. Society of Agronomy Inc., Publisher Madisson, Wilconsin, U.S.A., pp. 13721376.

Bouyoucos GJ (1955) A recalibration of the hydrometer method for making mechanical analysis of the soils. Agronomy Journal 4(9): 434.

Çıtak S, Sönmez S, Koçak F, Yaşin S (2011) Vermikompost ve ahır gübresi uygulamalarının ıspanak (Spinacia Oleracea Var. L.) bitkisinin gelişimi ve toprak verimliliği üzerine etkileri. Batı Akdeniz Tarımsal Araştırma Enstitüsü Derim Dergisi 28(1): 56-69.

Doğan K (2000) Antakya şehir çöplerinden elde edilen kompostun toprakların bazı fiziksel ve kimyasal özellikleri ile domateste verime etkisi. Doktora Tezi, Mustafa Kemal Üniversitesi Fen Bilimleri Enstitüsü, Hatay.

Ece A, Saltalı K, Eryiğit N, Uysal F (2007) The effects of leonardite applications on climbing bean (Phaseolus vulgaris L.) yield and the some soil properties. Journal of Agronomy 6(3): 480-483.

Evliya H (1964) Kültür bitkilerinin beslenmesi. Ankara Üniversitesi Ziraat Fakültesi Yayınları, Sayı: 10.

Eyüpoğlu F (1998) Türkiye topraklarının verimlilik durumu. Toprak Gübre Araştırma Enstitüsü. Genel Yayın No: 220.

Gezgin S, Dursun N, Hamurcu M, Ayaslı Y (1999) Konya ovasında şeker pancarı bitkisinde beslenme sorunlarının, Toprak ve Bitki Analizleri ile Belirlenmesi. Konya Pancar Ekicileri Koop. Eğitim ve Sağlık Vakfı Yayınları, Konya, s. 28-32.

Jackson MC (1967) Soil chemical analysis. Prentice Hall of India Private Limited, New Delhi.

Haynes RJ, Naidu R (1998) Influence of lime, fertilizer and manure applications on soil organic matter content and soil physical conditions: a review. Nutrient Cycling in Agro ecosystems 51: 123137. 
Kacar B (1972) Bitki ve toprağın kimyasal analizleri. II. Bitki Analizleri, A.Ü. Ziraat Fak. Yayınları: 453, Ankara.

Kacar B, Katkat V (2007). Ahır gübresinin olgunlaştırılması, Gübreler ve Gübreleme Tekniği, Nobel Yayınları, 28-32.

Kütük C, Çaycı G, Baran A, Baksan O (1999) Effect of humic acid on some soil properties. Soil Science Department, Agricultural Faculty, Ankara University, Ankara, s. 161.

Kütük C, Çaycı G, Baran A, Başkan O, Hartmann R (2003) Effects of beer factory sludge on soil properties and growth of sugar beet (Beta vulgaris saccharifera L.). Biosource Technology 90: 75-80.

Lindsay WL, Norvell WA (1978) Development of a DTPA soil test for Zinc, Iron, Manganese and Copper. Soil Sci. Amer. Jour. 42(3), 421-428.

Lopez HD, Aroujo Y, Lopez A, Hernandez VI, Hernandez C (2004) Changes in soil properties and earthworm populations induced by long-term organic fertilization of a sandy soil in the Venezuelan Amazonia. Soil Science 169(3): 188-194.

Okur N, Kayıkçığlu HH, Okur B, Delibacak S (2008) Organic amendment based on tobacco waste compost and farmyard manure: influence on soil biological properties and butter-head lettuce yield. Turkish Jounal of Agriculture \& Forestry 32: 91-99.
Olsen SR, Sommers EL (1982) Phosporus soluble in sodium bicarbonate. methods of soil analysis, Part 2, Chemical and Microbiological Properties. Edit: A.L. Page, P.H. Miller, D.R. Keeney, 404-430.

Sharif M, Ahmad M, Sarir MS, Khattak RA (2004) Effect of organic and inorganic fertilizers on the yield and yield components of maize. Pakistan Journal of Agriculture, Agricultural Engineering, Veterinary Sciences 20(1): 11-16

Shirani H, Hajabbasi MA, Afyuni M, Hemmat A (2002) Effect of farmyard manure and tillage systems on soil physical praperties and corn yield in central iran. Soil and Tillage Research 68: 101-108.

Vavoulidou E, Dimirkou A, Papadopoulos P, Avramides EJ, Arapakis D (2004) A comparative study for the control of organic agriculture in a region of greece. NAGREF Soil Science Institute of Athens. Symposium No: 57, Paper No.737. http://www.sfst.org/Proceedings/17WCSS_CD/Abstracts/0737.pdf.

Walter I, Martınez F, Cuevas G (2006) Plant and soil responses to the application of composted msw in a degraded, Semiarid Shrubland in Central Spain. Compost Science \& Utilization 14(2): 147-154. 